\title{
COVID-19 a health reform catalyst? - Analyzing single-payer options in the U.S.: Considering economic values, recent proposals, and existing models from abroad
}

\author{
Alan Parnell ${ }^{1}$, Krzysztof Goniewicz ${ }^{2}$, Amir Khorram-Manesh ${ }^{3,4}$, Frederick M. Burkle ${ }^{5}$, Ahmed Al-Wathinani ${ }^{6}$, Attila J. \\ Hertelendy*1 \\ ${ }^{1}$ Florida International University, Miami, FL, United States \\ ${ }^{2}$ Department of Aviation Security, Military University of Aviation, Dęblin, Poland \\ ${ }^{3}$ Department of Surgery, Institute of Clinical Sciences, Sahlgrenska Academy, Gothenburg University, Gothenburg, Sweden \\ ${ }^{4}$ Department of Development and Research, Armed Forces Center for Defense Medicine, Gothenburg, Västra Frölunda, Sweden \\ ${ }^{5}$ Harvard Humanitarian Initiative, T.H. Chan School of Public Health, Harvard University, Boston, MA, United States \\ ${ }^{6}$ Department of Emergency Medical Services, Prince Sultan Bin Abdulaziz College Emergency Medical Services, King Saud \\ University, Riyadh, Saudi Arabia
}

Received: June 17, 2020

DOI: $10.5430 /$ jha.v9n4p10
Accepted: July 29, 2020

Online Published: August 5, 2020

\begin{abstract}
The United States has continued to face severe health coverage and spending challenges that have been attributed to a fragmented multi-payer and fee-for-service delivery system which has become even more exposed by the COVID-19 pandemic. Legislators and healthcare professionals have tried to answer the challenges faced by the U.S. health system through the introduction of several state and federal proposals for a "Medicare-for-all" like system, which have failed to be adopted likely due to the lack of consideration for free-market economic values. Looking to existing models abroad can provide the U.S. with different ways to understand how to achieve the benefits of single-payer models with universal coverage while maintaining the integrity of free-market values. The health systems in wealthy, industrialized countries are closely referenced in this article because of the variation of methods in which each achieves a single-payer/universal coverage model as well as the contrast in their health outcomes compared to that of the U.S. The biggest considerations for any reform effort to achieve an efficient single-payer system with universal coverage is the maintenance of private health insurers and the degree to which expanded government influence would be accepted. The future state of health care remains uncertain and unstable as a result of the COVID-19 pandemic, therefore a window of opportunity exists now for leveraging this uncertainty to achieve reform.
\end{abstract}

Key Words: Payment reform, Single-payer reimbursement system, Universal health coverage, Medicare-for-all, National health service, COVID-19

*Correspondence: Attila J. Hertelendy, PhD; Email: ahertele@ fiu.edu; Address: Department of Information Systems and Business Analytics, College of Business, Florida International University. 11200 SW 8th St, Miami, FL 33199, United States. 


\section{INTRODUCTION}

As modern international health policy trends continue to emphasize systems characterized by universal health coverage under the scope of a single-payer model, the United States maintains a multi-payer system that is common to take blame for administrative fragmentation and excessively high health spending. Single-payer methods are often discussed as a way to answer for high health spending and care access challenges because of the association that a single entity administering coverage and reimbursement is more streamlined compared to a multi-payer system and could decrease excessive administrative costs while establishing a single standard for care delivery. Since the re-emergence of the idea of "Medicare-for-All", a system that has been popularized in the U.S. today by former democratic presidential candidate, Bernie Sanders, the reality, discovery and applicability of a single-payer and universal coverage model in the U.S. is commonly discussed in current literature. Notwithstanding, the literature commonly fails to review and tie back elements of a model that are consistent with that of American economic values; primarily free enterprise and freedom of choice. To seriously consider the applicability of a single-payer system with universal coverage in the U.S., analysis must focus on understanding existing models abroad and how they can be adapted to fit U.S. values.

The value of free enterprise in the U.S. and mixed methodology of government involvement is reflected in the current healthcare payer and reimbursement system. Healthcare is managed as a business in that patients act as consumers through cost-sharing and provider choice. ${ }^{[1]}$ Patients have the freedom to choose their healthcare provider, insurance provider, and coverage status. ${ }^{[1]}$ The U.S. maintains a multipayer reimbursement system in that administration, coverage and payment is managed through multiple agencies; both government and private firm's play a role. ${ }^{[1]}$ Reimbursement occurs primarily on a fee-for-service basis in that providers are reimbursed for the utilization of their services and not on the outcomes of services. ${ }^{[1]}$ The government plays a role in public coverage and private regulation. ${ }^{[1]}$ Public health coverage is managed at a federal and state level through the Centers for Medicare and Medicaid Services (CMS) and financed through taxation, premiums and cost sharing, with specific eligibility requirements for each CMS program. ${ }^{[1]}$ The government's regulatory role in financing and reimbursement in the private sector occurs through state-level marketplace requirements and through federal legislation such as the Affordable Care Act which has enabled minimum coverage standards and coverage violation penalties. ${ }^{[1]}$

The results yielded by this system compared against the expectations of the general public have subjected the current

Published by Sciedu Press state to considerable scrutiny and has opened the door for calls of dramatic reform. The U.S. spent $\$ 3.5$ trillion and \$3.65 trillion in 2017 and 2018 respectively, which exceeds the GDP of almost every country in the world. ${ }^{[2-5]}$ These numbers account for approximately $18 \%$ of the U.S. GDP and are expected to continue to grow under current legislative and industrial conditions. ${ }^{[2,3]}$ According to forecasted projections from CMS, healthcare spending is expected to grow 5.5\% per year from 2018 to 2027 and reach up to $\$ 6$ trillion in the same timeframe. ${ }^{[3]}$ Concurrent with high spending statistics, the actual costs of care present a larger issue that has implications for population health. A study done by the Kaiser Family Foundation found that approximately half of adults in the U.S., including those insured and uninsured, did not receive medical care they needed because of treatment costs. $^{[6]}$

Single-payer and universal coverage proposals have historically endured a partisan path; always introduced and supported by segments of the Democratic party (Universal Health Care Act, Expanded and Improved Medicare for all Act, etc.), they have failed to be implemented due to partisan gridlock with the Republican party or due to displaced attention focused on broader party initiatives such as Clinton's Health Security Act and Obama's Affordable Care Act. ${ }^{[7,8]}$ Characteristics of historical proposals in the U.S. often reflect those of recent proposals, including increased payroll taxes, abolishment of the private insurance industry, comprehensive coverage for all administered through a single government entity, and no cost-sharing for patients. ${ }^{[7,8]}$ These characteristics are largely not found in existing models abroad, especially abolishment of the private industry and cost-sharing, characteristics which virtually exist in some, varying capacity across all model countries referenced. Moreover, the characteristics of both historic and recent single-payer/universal coverage proposals deliver implications that can be perceived as extreme (abolishing private payers, and cost sharing, heavy tax increases, etc.) and have anchored partisan gridlock and inefficiency, therefore options should be pursued that are premised in real results and avoid extremities associated with past failures. ${ }^{[7,8]}$

Single-payer methods are a common theme in health reform literature and are usually mentioned as a recommended solution to the problems associated with U.S. healthcare today. ${ }^{[9]}$ Single-payer coverage and reimbursement methods are widely accepted as "heterogeneous" and variable in approach, however at its core it is recognized as a model in which coverage and reimbursement is administered by a single entity. ${ }^{\left[{ }^{[]}\right.}$This can often be associated with concepts such as universal health coverage in which health coverage spans across a whole population without any eligibility require- 
ments, as well as socialized medicine in which all aspects of healthcare system is administered by government, however one does not require the other. ${ }^{[9]}$ Single-payer models exist with variability in structure in countries such as Canada, the United Kingdom, Germany, France, the Netherlands, Australia, Sweden, Switzerland. ${ }^{[10]}$ Compared to these countries in areas such as overall care quality, access, efficiency, equity, and expenditure per capita, the U.S. ranks last in all areas, and has done so since 2004. ${ }^{[1-13]}$ Furthermore, single-payer models perform higher in equity, risk pooling and the reduction of administrative costs, while multi-payer systems maintain higher bargaining power and freedom of choice for patients, values essential to the American economy and way of life. ${ }^{[14]}$ Given the performance of single-payer models showing consistently stronger results across multiple dimensions of healthcare, it is a viable reform option for the U.S. to explore. ${ }^{[15]}$ The COVID-19 pandemic that began in early 2020 has had a deleterious effect on healthcare, notwithstanding a tremendous financial impact on healthcare systems. ${ }^{[16]}$ The pandemic's full impact remains unknown, however the traditional fee for service and payment models come under additional stress and scrutiny as a result. ${ }^{[1]}$ For at least the past 75 years, single payer models have been a part of the national debate. Other than Medicare, efforts to establish federally run national health insurance schemes have failed in Congress. ${ }^{[18]}$ As a result the US has a patchwork of private and public programs which unto themselves create unnecessary complications for reform. Since 1975 efforts towards single-payer health reform have been mired in incrementalism. ${ }^{[19]}$

COVID-19 maybe a catalyst for considering necessary reform in the U.S., the key components of a single-payer reimbursement system, and the variability in which these components can be managed, may embolden policymakers to embrace necessary changes to protect both the economic viability of the healthcare system writ large and create a pathway to affordability. ${ }^{[20]}$

This study aims to review a series of options for the implementation of a single-payer system in the U.S. by turning to models abroad, reviewing recent proposals and seeking to maintain free-market values.

\section{OPTIONS FOR ANALYSIS}

Health system administration models are presented to give a comparative view and conceptual take into system administration and government influence, eligibility, benefits, financing, cost sharing, the role of private payers, and references for existing and proposed models. The models may represent components of recently proposed legislation, a currently operating system in another country, or combinations of the two. The first two models are presented to give insight into recent proposals for single-payer reform and the third and fourth models are presented to highlight how the U.S. can adopt considerably different models of single-payer that explore the utilization of state-level administration and the re-alignment of an existing and thriving private insurance industry. Analysis of potential outcomes is provided for each option according to the most recent data of the model countries referenced in each option. See Appendix (Exhibit 1) for a comparative view of all options. See Appendix (Exhibit 2) for a comparative view of system performance of model countries for each option, including the current system performance of the U.S.

\subsection{Medicare-for-all}

As a precursor to reviewing conceptual options modeled after existing systems abroad, we analyzed the most recent single-payer proposals in the U.S. to benchmark the current perception of what a single-payer model in the U.S. would reflect, and how universal coverage can be achieved. Since 2010, 20 states have introduced legislation to implement single-payer systems with universal coverage. ${ }^{[21]}$ At the federal level, there have been ten proposals for Medicare-for-all or some similar facet of Medicare and public health expansion between the 115 th and 116 th Congress's. ${ }^{[22]}$ The most notable of recent Medicare-for-all proposals are those submitted by Senator Bernie Sanders and Representative Pramila Jayapal, both of which are national-level proposals, would encompass universal health coverage for all services and would be financed solely through taxation with virtually no cost sharing. ${ }^{[21]}$

Under the Sanders-Jayapal models all citizens are eligible and automatically enrolled under federal coverage as mandated by an insured citizens requirement. ${ }^{[22]}$ The government will be the sole proprietor of coverage administration and reimbursement for services and will replace all other health insurance providers including Medicaid, but retaining, Veterans Affairs and Indian Health Service as they are currently operated. ${ }^{[22]}$ Benefits will include all medically necessary services including services for dental, mental health, vision and hearing. ${ }^{[22]}$ Those who are disabled will qualify for coverage of transportation to health service appointments. ${ }^{[22]}$ This model will require periodic reviews from the Secretary of Health to make recommendations on program optimization and expansion. ${ }^{[22]}$ States will be allowed the flexibility to provide further coverage at their own expense. ${ }^{[22]} \mathrm{Fi}^{-}$ nancing will occur through expanded national taxation and would incur no-cost sharing which includes no premiums, deductibles, or co-pays for any covered services. ${ }^{[22]}$ This model is predicted to save upwards of $\$ 500$ billion in overall 
spending per year through the containment of administrative costs associated with multi-payer systems, and complete abolishment of the private health insurance industry, despite a $1 \%$ allocation of global budget to accommodate displaced employees. ${ }^{[17,23]}$

Among the world's wealthy and industrialized countries, none exist which directly mirror a nationally funded and provisioned system in which cost sharing and private payers do not play any role. ${ }^{[10]}$ The most similar comparison can be drawn to the French statutory health insurance (SHI) system given certain structural similarities to Medicare-for-all. ${ }^{[24]}$ The French healthcare system is nationally funded and administered through SHI, which is national health coverage that is strategically designed to influence health expenditures and utilization. ${ }^{[24]}$ This system is financed through employer/employee taxation, income taxes, and various industrial taxes and provider ownership is mixed between public and private. ${ }^{[24]}$ Coverage is mostly comprehensive for medically necessary services, however moderate cost-sharing does exist through supplemental coverage offered by employers for rehabilitative services, pharmaceuticals, and dental services. ${ }^{[11]}$ Inexpensive co-payment rates also exist for lists of standard services. ${ }^{[24]}$

Implementing a Medicare for All strategy or a single payer solution is significantly complicated by politics. Scholars intimate the United States Senate remains the largest stumbling blocks in the years ahead for any incremental movement towards a single payer system. ${ }^{[7,25]}$

\subsection{Federally Managed National Health Service with coverage options}

The British National Health Service (NHS) is recognized as the top-overall rated health system among wealthy, developed countries and can be used as a model for the U.S. to implement a federally managed health service that maintains supplementary, complementary, and substitutive private coverage options. ${ }^{[14,26]}$ Under the NHS, healthcare services are administered at the national level through the standards set-forth by the NHS Constitution, with shared responsibility between the Department of Health and NHS England. Coverage is largely comprehensive which includes mental health services. ${ }^{[2]}$ Provider and hospital ownership are mixed between public and private. ${ }^{[26]}$ Cost sharing is minimal in that, while copays are required for few services at the point of service, most cost-sharing expenditures come from pharmaceuticals. ${ }^{[26]}$ Private payers exist in a complementary capacity that cover non-covered services, as well as in a comprehensive/substitutive capacity that gives enrollees expanded access to quicker and often higher quality care. ${ }^{[26]}$

Published by Sciedu Press
The NHS structure resembles a form of Medicare expansion introduced by Representative DeLauro and Representative Schakowsky in H.R. 2452, known as the "Medicare for America Act of 2019". ${ }^{[22]}$ This proposal suggests a federally administered public benefits program with comprehensive coverage in which cost sharing is minimal. ${ }^{[22]}$ This proposal also seeks to maintain the presence of private insurance offered through employers and eliminate the state-marketplace. ${ }^{[22]}$ This method would be financed by premiums and employer payroll taxes however spending reductions are unclear. ${ }^{[22]}$

Applying these methods to the U.S. results in a system that is financed and administered through the federal government and satisfies the standard for universal health coverage through public health coverage options and a mandated insured citizens requirement, while maintaining private payers in complimentary and substitutive capacities. Through federal eligibility administration, all citizens will be eligible and automatically enrolled in a basic coverage package. ${ }^{[22,26]} \mathrm{Se}-$ nior citizens (ages 65 and older), and the chronically ill and disabled meeting specified medical criteria, are eligible and automatically enrolled in comprehensive coverage. ${ }^{[22,26]}$ Any citizen not medically eligible for comprehensive coverage will have the option to enroll in a comprehensive package and incur further cost sharing through deductibles and increased premium deductions from payroll. ${ }^{[22,26]}$ All citizens will have the option to opt-out of the federal health service program, so long as they enroll in employee-sponsored health insurance, thus maintaining the integrity of the insured citizen requirement and standard of universal health coverage. ${ }^{[22,26]}$ A mixed presence of public and private providers and hospital ownership will be maintained in this option, however standards for service utilization must be set-forth by federal regulation with the guidance, consultation, and oversight of healthcare interest groups, non-government organizations (NGO's) and not-for-profit healthcare organizations such as the Joint Commission (JCAHO) and the National Committee for Quality Assurance (NCQA) ${ }^{[22,26-29]}$

Basic coverage packages will include some preventative care, emergency services, standard physician services, medically necessary specialty services, some pharmaceuticals and some mental health services. ${ }^{[2,26]}$ In the basic coverage package, cost-sharing exists only through minimal and inexpensive copays, as to generate some form of revenue that can be cycled back into the system and ease taxation financing. ${ }^{[22,26]}$ Comprehensive coverage will include all services offered in the basic coverage option as well as vision services, dental services, hearing services, non-emergency hospital care, and higher access to preventative care, physician services, pharmaceuticals and mental health services. ${ }^{[22,26]}$ For those eligible for comprehensive coverage via the age requirement 
or by meeting defined medical criteria for disability and/or chronic illness, cost sharing will be minimal for select services/pharmaceuticals via copayments at the point of service. ${ }^{[22,26]}$ Offering comprehensive coverage as an upgrade through public health will enable the government's bargaining power by establishing itself as a competitor of private payers as well as strengthening its position in leading delivery standards. ${ }^{[22,26,30]}$ Comprehensive coverage will be designed as an extended effort to improve population health and healthcare spending by enabling a lost-cost option to address preventative and ongoing health measures. ${ }^{[22,26,31]}$

Under this model, private payers continue to exist in varying capacities. As to avoid the variations and complexities involved with state-regulated insurance marketplaces, private insurance will be offered exclusively through employersponsored health plans. ${ }^{[22,26]}$ These plans can be supplementary to basic and comprehensive coverage by picking up remaining out-of-pocket costs, complementary to basic coverage by covering non-covered services, or substitutive in covering all services for citizens who choose to opt-out of the federal health service. ${ }^{[22,26]}$ Private insurance will need to meet certain minimum coverage requirements according to the category of coverage (supplementary, complementary, substitutive) offered, as well as maintain a certain cost-sharing and spending threshold, all of which will be set-forth by federal regulations. ${ }^{[22,26]}$

This model will be financed through taxation that varies by employment status (part-time, full-time, selfemployed). ${ }^{[22,26]}$ Citizens enrolled in employer-sponsored private insurance will receive tax breaks for enrollment in supplementary and complementary coverage and will be exempt from NHS program specific payroll taxes for enrollment in private comprehensive coverage. ${ }^{[22,26]}$

\subsection{State administered health insurance that is federally regulated}

The Canadian system can be studied as a model to explore regionally managed healthcare administration. The Canadian system ranks 9th in overall health system performance among high-income, developed countries, accounting for $\$ 4,728$ expenditure per capita. ${ }^{[14,32]}$ Looking to the Canadian healthcare system enables the U.S. to explore a reform option that empowers the states as the primary administrators of healthcare while the federal government sets forth national regulatory standards for state systems as well as contributes to partial funding. In the Canadian system, healthcare is administered and funded by each province, while the national government's role is to oversee administration at a high level, legislate minimum coverage standards, and issue funding grants based on the satisfaction of national admin- istration requirements. ${ }^{[32]}$ Like the Canadian system, the U.S. federal government will need to mandate universal and comprehensive coverage standards, ease of accessibility, and transferability across state lines, then grant funds to each state meeting the minimum requirements with variability based on population density. ${ }^{[32]}$

In this model, all state residents are eligible and automatically enrolled in their state's minimum coverage programs. ${ }^{[32]}$ U.S. citizens that are visiting a state they are not a resident of will have coverage for emergency and urgent care services with costs being passed along to the individual's state of residence. Resembling the Canadian benefit package, the minimum requirements for coverage will include "medically necessary physician, diagnostic, and hospital services," as well as coverage for in-patient pharmaceuticals. ${ }^{[32]}$ As with financing options, states may provide coverage for additional services at their discretion. ${ }^{[33]}$

In Canada, $67 \%$ of the population is covered under some form of private health insurance (the grand majority through employers), accounting for $30 \%$ of total health expenditures therefore demonstrating the need for private payers in the U.S. to remain in existence under this model. ${ }^{[10]}$ Given the guarantee for basic coverage at the public level, private payers will offer complementary coverage, picking up the costs for services not included in the public benefit package of each state. ${ }^{[32]}$ Private insurance will be offered mainly through employer groups and community organizations, while the state marketplace will cease to exist, given the auto-enrollment in state public health coverage programs. ${ }^{[32]}$

Financing will occur through state-level tax revenue, as well as federally funded grants paid to states meeting coverage requirements that are financed through federal payroll taxes. States will have the freedom to explore additional financing options at their discretion so long as it is compliant with federal regulations. ${ }^{[32]}$ Cost-sharing will vary significantly by state and service, however no cost sharing will occur for services meeting the minimum requirements for public funding (physician, hospital, diagnostic, and in-patient pharmaceuticals). ${ }^{[32]}$

\subsection{Private insurers regulated by government}

The Dutch and German systems, ranking third and eighth in overall health system performance and accounting for $\$ 5,227$ and $\$ 5,119$ in health spending per capita, present a case for the U.S. to understand how to configure their existing state of multiple, private payers with re-aligned federal participation and universal coverage requirements. ${ }^{[14,34,35]}$ These models represent a system in which administration occurs primarily through private insurers while the national government plays 
a minimal role, focusing on regulation and financing. Different from an NHS model, these systems are administered through private insurers who offer statutory health insurance (SHI) which receives funding from the national government and is financed through general and payroll taxation. ${ }^{[34,35]}$ The role of the national government is to oversee healthcare system performance and legislate as necessary to maintain effective access, quality, and spending outcomes. ${ }^{[34,35]}$ The government relies on interest groups, NGO's and accreditation organizations to define system goals and minimum coverage standards. All citizens and residents are eligible for coverage through SHI and must enroll through an SHI provider in the state market-place or through an employer sponsored plan. ${ }^{[35]}$ All SHI providers are required to approve and accept any applicants. ${ }^{[35]}$

In the German/Dutch referenced model, private payers are required to offer a basic coverage option through SHI which receives funding from the federal government. The basic coverage requirements are defined by public health agencies, such as the National Health Care Institute in the Netherlands and the Federal Joint Committee in Germany. ${ }^{[34,35]}$ In the U.S., the government can refer to entities such as JCAHO, the American Hospital Association (AHA), and the NCQA. ${ }^{[27-29]}$ Basic coverage requirements include most medically necessary services, with variations in specialist services, pharmaceuticals, and mental health services, as defined by the advising entities of the government. ${ }^{[36]}$ Private payers also offer complementary coverage options to cover non-covered services, as well as substitutive coverage for citizens choosing to opt-out of the SHI option. In the Netherlands, $84 \%$ of the population pays for complementary coverage while in Germany $11 \%$ of the population is enrolled in substitutive coverage therefore establishing variations in the roles private payers can play in this model. ${ }^{[34,35]}$

Federal payments to private payers are financed through payroll taxation and general tax revenue. Payroll taxation percentages will vary by employment status, income, and demographics. Financing will also come from recycled revenue generated through deductibles and point-of-service copayments. The annual deductible will include costs for most healthcare services and would often be met through co-payments, however select services will require point-ofservice fee payments regardless of a satisfied deductible. In the Netherlands, the annual deductible amounts to $\$ 465$ which is of considerable difference compared to that of the U.S. which is $\$ 1,846$ for individuals and $\$ 3,392$ for families. ${ }^{[35,37]}$

Given a minimal role of government in administration and delivery, the presence of private providers and hospital own-

Published by Sciedu Press ership is maintained as well as is industrial competition and bargaining power. ${ }^{[30]}$ Universal coverage will be achieved through an insured citizen's requirement, thus improving care access, which is synonymous with all previous options. Existing federal and state coverage programs will be virtually abolished, with pre-existing funding now being re-directed to not-for-profit private payers offering SHI. The consolidation of existing public programs should ease administrative costs and put care delivery initiatives in the hands of not-for-profit NGO's and public health agencies such as the AHA and JCAHO. The maintenance of private insurers also enables patient freedom of choice of provider and insurer. ${ }^{[14]}$

\section{Discussion}

Legislators and policy advocates should reference models abroad when drafting health coverage and reimbursement legislation by way of a single payer/universal coverage structure that respects free-market values and should accept the heterogeneity of existing systems. Consideration must be given to what a single-payer /universal coverage model would truly mean for the U.S. While the economic implications are widely variable to the different models referenced, any case would mean expanded government control and influence in an existing private sector - something that the American general population is inherently skeptical of.

The Sanders-Jayapal "Medicare-for-all" model would require the furthest degree of expanded government influence compared to other models and with it would bring the displacement of hundreds of thousands of jobs and hundreds of billions of dollars in revenue. This does not readily align with the free-market economy, especially considering twothirds of the population have coverage through private insurance. ${ }^{[38]}$ Its lack of acceptance has been made apparent by Congress through their non-adoption of submitted legislation, the states for the same reason, and the general public given unsuccessful presidential campaign attempts for candidates such as Bernie Sanders and Elizabeth Warren who marketed Medicare-for-all as the platform of their campaigns. In addition, the abolishment of the private insurance industry would eliminate industrial competition in the healthcare market which would impact bargaining power, creating concern around increased healthcare costs. ${ }^{[14,30]}$ The preservation of private payers in some capacity should be a top consideration given its alignment with the value of choice in a free-market economy and its presence in existing singlepayer/universal coverage models. ${ }^{[10,14,24,26,32,34,35]}$ On the other end of the spectrum, the "Government Regulated Private Insurer's" model would preserve competition and is likely to result in the least economic disruption given that it can be implemented with little to no job or revenue displace- 
ment compared to the Medicare-for-all model and is likely the easiest to adapt because its structure resembles that of the current state. ${ }^{[1,14,34,35]}$ Consideration must be given to whether this model is actually enough reform to solve for the issues of the current state and if it truly embraces the necessary change to merit a reformed model. ${ }^{[3-6,10-12]}$

Another important consideration for legislators and healthcare professionals is that expanding government influence and control by way of a single payer/universal coverage system would subject the system's efficiency and effectiveness to the degree in which government is involved. ${ }^{[14,39]}$ In a system with near absolute government influence, an ineffective or corrupt administration would likely result in an ineffective or corrupt healthcare system, which would contradict the goals of reform. ${ }^{[14,39]}$ The system would also be subject to inconsistencies that may result from changes in administrative partisanship; therefore, controls must be put in place to ensure operational consistency across partisan differences. ${ }^{[39]}$ In turn, assigning the core of administrative responsibilities to the states, as is referenced in the third model, may result in cases of misalignment between a state's values and federal healthcare requirements, especially in cases where the administration of the state in question opposed the specifications of national health reform. ${ }^{[14]}$ This would also likely result in system inefficiencies and may pose the question of whether this model reflects too many layers of government to actually be effective. To gauge the degree in which federal and state government influence over healthcare should be expanded, stakeholders should study how the varying levels of government have responded to the COVID-19 pandemic, as the endurance and efficiency of the current-state system and its relationship to the economy have been exposed during the pandemic and present an opportunity for policy advocates to use this exposure as leverage for true reform.

One delivery strategy to consider that would enable expanded access in an effort to accommodate a universal coverage system and moldable to almost any coverage and reimbursement structure is telehealth. Telehealth enables patient access to care in the most convenient way for the patient without having to leave their home and simplifies the patient appointment process for providers. Telehealth has grown considerably in utilization, with a $40 \%$ increase in use by hospitals between 2010 and 2017. ${ }^{[40,41]}$ Telehealth presents an opportunity for anybody with a phone or access to a computer to receive medical attention, and because it requires virtually no facility or equipment costs, should be seriously considered as a platform for achieving universal coverage. ${ }^{[41]}$ Telehealth has been proven to be readily adaptable in the COVID-19 pandemic response by providers, it therefore lays the groundwork for long-term and sustainable utilization for expanded healthcare access at the national level. ${ }^{[41]}$

As of July 2020, the U.S. has the largest number of officially confirmed COVID-19 cases in the world by a difference of nearly 1.2 million, despite a series of measures put in place by federal and state governments to slow the spread of the virus. ${ }^{[42,43]}$ The large number of cases coupled with the guidelines put in place by government has led to severe economic impacts across all industries and markets. In the healthcare industry specifically, the impact of COVID-19 has been detrimental, with projected losses in hospital revenue of over \$200 billion between March and June 2020, largely attributed to the cessation of elective medical services, and forecasted additional costs ranging between $\$ 56$ billion and $\$ 860$ billion over the course of the next two years. ${ }^{[4-46]}$ These numbers have inevitably put hospitals and health systems in vulnerable positions, some of which are filing bankruptcy as a result while others struggle with shortages in capacity and resources to treat the overwhelming cases of COVID-19. ${ }^{[47-49]}$ Healthcare's current and foreseeable state of financial instability has also taken a considerable toll on private health insurers, as well as employers offering private coverage, facing additional estimated costs of up to $\$ 650$ billion due to the pandemic. ${ }^{[17]}$ Recommendations for relieving insurers of the challenges ahead have been introduced as low-interest federally guaranteed loans, however the current industrial and financial conditions in healthcare present the opportunity to introduce value-based purchasing as a legitimate and more sustainable option so that insurers have a larger stake in patient costs and outcomes. ${ }^{[17]}$ The severity in which COVID-19 has impacted the U.S. and the uncertainty that is maintained as each day goes on suggests an existing system that is unfit to properly manage large-scale medical crises, and has led to the scrutiny of the government's response. The state of the current healthcare environment and ambiguity surrounding the future of healthcare present an opportunity for reform advocates to leverage a system that has been exposed as underprepared and ill-equipped as a catalyst for reform. ${ }^{[50]}$

\section{COVID 19 - Health reform considerations for the United States}

COVID-19 stimulus packages will eventually run out and individual consumers and employers are already experiencing affordability challenges in the U.S. The pandemic exposes significant vulnerabilities in the healthcare system, including stark economic consequences related to inadequate insurance coverage and access to care magnified by many people losing both their jobs and access to employer sponsored healthcare. ${ }^{[51,52]}$

Numerous reports of surprise medical billing where a patient 
is forced to get treatment from outside their network due to provider shortages may be exacerbated during the crisis. Policymakers must step into protect the public and eliminate billing from out of network provider that exceed in-network limits for medical treatments received during pandemic and consideration should be given to creating permanent legislation to curb surprise billing. ${ }^{[50,53]}$

\section{Conclusions}

Current policy and literature discussing health reform in the U.S. is consistent in discussing mechanisms to answer the challenges of healthcare through the introduction of a singlepayer coverage and reimbursement model. ${ }^{[54]}$ Similar models have been introduced at state and federal levels, yet none have been fully implemented. While there is considerable variability across proposed models as well as with existing models abroad, achieving universal health coverage while maintaining some presence of private payers is a dominant theme of existing single-payer systems. The U.S. must look abroad to understand the variability of single-payer models while considering the associated economic implications of expanding government's role in healthcare. For reform to occur, the U.S. must adopt a model that is their own and reflects the economic values of the free-market. While previous attempts at reform have been unsuccessful because of misalignment between proposed reform and the values of government and the general population, the impact of
COVID-19 on the current-state and ambiguous future-state of health care presents an opportunity to introduce meaningful reform that will establish new delivery, coverage and reimbursement standards. As the 2020 election nears, COVID-19 cases continue to rise in the U.S. while ambiguity continues to surround solutions on how to best manage this pandemic, making economic recovery an arduous topic. As a result, the state of healthcare, the economy, and how the two intertwine, will be central political themes that the public will demand comprehensive solutions for. ${ }^{[55]}$ Messaging that refocuses public opinion on the benefits of a single payer system remains a key strategy as the main barrier to reform remains political and according to a recent KFF poll public opinion remains high for some type of public option that provides universal coverage. ${ }^{[56]}$ Historically, major healthcare reform required a catalyst such as a major war, a depression, or large-scale civil unrest that changed the political balance. The COVID-19 pandemic may provide the impetus for major political change and create an opportunity for major health reform to be achieved. ${ }^{[55,57,58]}$

\section{FUNDING SOURCE}

This research did not receive any specific grant from funding agencies in the public, commercial, or not-for-profit sectors.

\section{CONFLICTS OF INTEREST Disclosure}

The authors declare they have no conflicts of interest.

\section{REFERENCES}

[1] Commonwealth Fund. International Health Care System Profiles: The U.S. Health Care System. 2016. Available from: https://international. commonwealthfund.org/countri es/united_states/

[2] Centers for Medicare and Medicaid Services. National Health Accounts Historical. 2018a. Available from: https://www.cms.gov/Research-Statistics-Data-and-S ystems/Statistics-Trends-and-Reports/NationalHealt hExpendData/NationalHealthAccountsHistorical.html

[3] Centers for Medicare and Medicaid Services. National Health Expenditure Projections 2018-2027. 2018b. Available from: https://www.cms.gov/Research-Statistics-Data-and-S ystems/Statistics-Trends-and-Reports/NationalHealt hExpendData/Downloads/ForecastSummary.pdf

[4] Herman B. The U.S. Spent $\$ 3.65$ Trillion on Health Care in 2018, and Higher Spending Won't Slow Down. 2019. Available from: https://www.axios.com/health-care-spending-2018-h ospitals-doctors-drugs-economy-b520930a-0cd9-4c6 8-9dd1-f31cc08ec264.html

[5] Sherman E. U.S. Health Care Costs Skyrocketed to \$3.65 Trillion in 2018. 2019. Available from: https://fortune.com/2019/02/ 21/us-health-care-costs-2/

Published by Sciedu Press
[6] Kirzinger A, Munana C, Wu B, et al. Data Note: Americans' Challenges with Health Care Costs. 2019. Available from: https://www.kff.org/health-costs/issue-brief/d ata-note-americans-challenges-health-care-costs/

[7] McDonough J. Medicare For All: What History Can Tell Us About its Chances. Health affairs. 2020.

[8] History of Single-Payer Legislation. Healthcare-Now!. 2020. Available from: https://www.healthcare-now.org/legislation /national-timeline/

[9] Liu JL, Brook RH. What is Single-Payer Health Care? A Review of Definitions and Proposals in the U.S., Journal of General Internal Medicine. 2017; 32(7): 822-831. PMid: 28493177. https://doi.org/10.1007/s11606-017-4063-5

[10] Glied S, Black M, Lauerman W, et al. Considering "Single Payer" Proposals in the U.S.: Lessons from Abroad. Issue Brief, Commonwealth Fund. 2019; 1-10. Available from: http://ezproxy.fiu.edu/login?url=https: //search-proquest-com.ezproxy.fiu.edu/docview/221 0960005 ? accountid=10901

[11] Commonwealth Fund. U.S. Health System Ranks Last Among Eleven Countries on Measures of Access, Equity, Quality, Efficiency, and Healthy Lives. 2014. Available from: https://www . commonwealthfund.org/press-release/201 
4/us-health-system-ranks-last-among-eleven-countri es-measures-access-equity

[12] Schneider E, Sarnak D, Squires D, et al. Mirror, Mirror 2017: International Comparison Reflects Flaws and Opportunities for Better U.S. Health Care. 2017. Available from: https://interactives .commonwealthfund.org/2017/july/mirror-mirror/

[13] Morgan SG, Good CB, Leopold C, et al. An analysis of expenditures on primary care prescription drugs in the United States versus ten comparable countries. Health Policy. 2018. PMid: 30041827. https://doi.org/10.1016/j.healthpol.2018.07.005

[14] Petrou P, Samoutis G, Lionis C. Single-Payer or a Multipayer Health System: A Systematic Literature Review. Public Health. 2018; 163 141-152. PMid: 30193174. https://doi.org/10.1016/j.puhe .2018 .07 .006

[15] Fox A, Poirier R. How single-payer stacks up: evaluating different models of universal health coverage on cost, access, and quality. International Journal of Health Services. 2018. PMid: 29925286. https ://doi.org/10.1177/0020731418779377

[16] Barnett ML, Mehrotra A, Landon BE. Covid-19 and the Upcoming Financial Crisis in Health Care. NEJM Catalyst Innovations in Care Delivery. 2020; 1(2).

[17] Bloche G, Wikler D. Could Coronavirus Cause the Collapse of Our Healthcare Financing System? 2020. Available from: https://www.healthaffairs.org/do/10.1377/hblog 20200504.8791/full/

[18] Greer SL, Jarman H, Donnelly PD. Lessons for the United States from single-payer systems. American Journal of Public Health. 2019; 109(11): 1493-1496. PMid: 31536407. https://doi.org/10.2 105/AJPH. 2019.305312

[19] Oberlander J. Lessons from the long and winding road to Medicare for All. American Journal of Public Health. 2019. PMid: 31536401 https://doi.org/10.2105/AJPH. 2019.305295

[20] Frakt AB, Oberlander J. Challenges to Medicare For All Remain Daunting: Medicare For All universal coverage proposals are not viable unless they overcome political, economic, and administrative realities that govern US health care. Health Affairs. 2020. PMid 31905071. https://doi.org/10.1377/hlthaff . 2019.01494

[21] Fuse-Brown E, McCusky E. Could States do Single-Payer Health Care? Health Affairs Blog. 2019.

[22] Kaiser Family FoundationCompare Medicare-for-all and Public Plan Proposals. 2019. Available from: https://www.kff.org/interactive/compare-medicar e-for-all-public-plan-proposals/?gclid=CjwKCAjwib zsBRAMEiwA1pHZroen3xcG1mThcv0kHZmmo6zVWVLh9HdcR4q4 3b-fS9_3ESVqo9kN0xoCv1MQAvD_BwE

[23] Medicare For All 2019 Summary (n.d.). Available from: https://www. sanders. senate.gov/download/medicare-f or-all-2019-summary?id=FA52728F-B57E-4EOD-96C2-FOC 5D346A6E1\&download=1\&inline=file

[24] Durand-Zaleski I. International Health Care System Profiles: The French Health Care System. 2016. Available from: https ://inte rnational. commonwealthfund.org/countries/france/

[25] Peterson MA. Enacting Medicare for All: Balancing Ambition With the Needs of Statecraft. American Journal of Public Health. 2019. PMid: 31577498. https://doi.org/10.2105/AJPH. 2019.30 5339

[26] Thorlby R, Arora S. International Health Care System Profiles: The English Health Care System. 2016. Available from: https://inte rnational . commonwealthfund.org/countries/england/

[27] American Hospital Association. (n.d.). About the AHA. Available from: https://www.aha.org/about
[28] JCAHO. (n.d.). About the Joint Commission. Available from: https://www.jointcommission.org/about_us/about_the _joint_commission_main.aspx

[29] NCQA. (n.d.). About NCQA. Available from: https : //www.ncqa .org/about-ncqa/

[30] Stadhouders N, Kruse F, Tanke M, et al. Effective Healthcare Cost-containment Policies: A systematic Review. Health Policy. 2019. PMid: 30429060. https://doi.org/10.1016/j.health pol.2018.10.015

[31] Nicaise P, Giaccob D, Soltmann B, et al. Healthcare system performance in continuity of care for patients with severe mental illness: A comparison of five European countries. Health Policy. 2020; 124(1): 25-36. PMid: 31831211. https://doi.org/10.1016/j.health pol.2019.11.004

[32] Allin S, Rudoler D. International Health Care System Profiles: The Canadian Health Care System. 2016. Available from: https : //in ternational . commonwealthfund.org/countries/canada/

[33] Guo EX, Sweetman A, Guindon GE. Socioeconomic differences in prescription drug supplemental coverage in Canada: A repeated cross-sectional study. Health Policy. 2019. PMid: 31952864. https : //doi.org/10.1016/j.healthpol.2019.12.007

[34] Blumel M, Busse R. International Health Care System Profiles: The German Health Care System. 2016. Available from: https://inte rnational . commonwealthfund.org/countries/germany/

[35] Wammes J, Jeurissen P, Westert G, et al. International Health Care System Profiles: The Dutch Health Care System. 2016. Available from: https://international. commonwealthfund.org/cou ntries/netherlands/

[36] Tuohy CH. Political Accommodations in Multipayer Health Care Systems: Implications for the United States. American Journal of Public Health. 2019. PMid: 31536406. https : //doi .org/10. 210 5/AJPH . 2019.305279

[37] Kaiser Family Foundation. Average Annual Deductible Per Enrolled Employee in Employer-based Health Insurance for Single and Family Coverage. 2020. Available from: https://www.kff.org/other/state-indicator/average -annual-deductible-per-enrolled-employee-in-emplo yer-based-health-insurance-for-single-and-famil $y$-coverage/? currentTimeframe=0\&sortModel $=\{$ "colId" : "Location", "sort" : "asc"\}

[38] U.S. Census Bureau. Health Insurance Coverage in the United States: 2018. 2019. Available from: https://www.census.gov/libra ry/publications/2019/demo/p60-267.html

[39] Rice T, Unruh LY, van Ginneken E, et al. Universal coverage reforms in the USA: From Obamacare through Trump. Health Policy. 2018. PMid: 29804633. https://doi.org/10.1016/j.health pol.2018.05.007

[40] American Hospital Association. Fact sheet: Telehealth: AHA. 2019. Available from: https://www.aha.org/factsheet/teleheal th

[41] Brody JE. A Pandemic Benefit: The Expansion of Telemedicine. New York Times. 2020. Available from: https://www.nytimes.com/2020/05/11/well/live/c oronavirus-telemedicine-telehealth.html

[42] John Hopkins University. COVID-19 Map.2020. Available from: https://coronavirus.jhu.edu/map.html

[43] Coronavirus Guidelines for America. 2020. Available from: https : //www. whitehouse.gov/wp-content/uploads/2020/ 03/03.16.20_coronavirus-guidance_8.5x11_315PM.pdf

[44] American Hospital Association. Hospitals and Health Systems Face Unprecedented Financial Pressures Due to COVID-19.2020. Available from: https://www.aha.org/system/files/media 
/file/2020/05/aha-covid19-financial-impact-0520-F INAL.pdf

[45] Cohen M, Whittal K, Murray T. COVID-19 Cost Scenario Modeling - AHIP. 2020. Available from: https ://www .ahip.org/wp-con tent/uploads/AHIP-COVID-19-Modeling ·pdf

[46] Bartsch S, Ferguson MC, McKinnell JA, et al. The Potential Health Care Costs and Resource Use Associated with COVID-19 in the United States. Health Affairs. 2020. PMid: 32324428. https: //doi.org/10.1377/hlthaff.2020.00426

[47] Ronalds-Hannon E, Coleman-Lochner L. Quorum's 24 Hospitals Face Bankruptcy Amid COVID-19 Pressure. 2020. Available from: https : //www . bloomberg. com/news/articles/2020-04-0 3/quorum-s-24-hospitals-facing-bankruptcy-amid-cov id-19-onslaught

[48] Jacobs A, Richtel M, Baker M. 'At War With No Ammo': Doctors sSay Shortage of Protective Gear is Dire. New York Times. 2020. Available from: https://www.nytimes.com/2020/03/19/hea lth/coronavirus-masks-shortage.html

[49] Ranney ML, Griffeth V, Jha AK. Critical Supply Shortages - The Need for Ventilators and Personal Protective Equipment During the COVID-19 Pandemic: NEJM. 2020. PMid: 32212516. https: //doi.org/10.1056/NEJMp2006141

[50] King JS. Covid-19 and the need for health care reform. New England Journal of Medicine. 2020. PMid: 32302074. https ://doi .org/ 10.1056/NEJMp2000821

[51] Levitt L. COVID-19 and Massive Job Losses Will Test the US Health Insurance Safety Net. JAMA Health Forum. 2020. Avail- able from: https://jamanetwork.com/channels/health-f orum/fullarticle/2766729

[52] Maani N, Galea S. COVID-19 and Underinvestment in the Health of the US Population. The Milbank Quarterly. 2020. PMid: 32333451. https://doi.org/10.1111/1468-0009.12462

[53] Sheckter CC, Singh P, Angelos P, et al. Surprise Billing in Surgical Care Episodes-Overview, Ethical Concerns, and Policy Solutions in Light of COVID-19. Annals of Surgery. 2020. PMid: 32520741 https://doi.org/10.1097/SLA.0000000000004152

[54] Brown LD. Single-Payer Health Care in the United States: Feasible Solution or Grand Illusion? American Journal of Public Health 2019. PMid: 31577485. https://doi.org/10.2105/AJPH. 201 9.305315

[55] Fuchs VR. Health Care Policy After the COVID-19 Pandemic. JAMA 2020. PMid: 32530458. https://doi.org/10.1001/jama. 202 0.10777

[56] Kaiser Family Foundation. Public Opinion on Single-Payer, National Health Plans, and Expanding Access to Medicare Coverage. 2020. Available from: https://www.kff.org/slideshow/public-o pinion-on-single-payer-national-health-plans-and-e xpanding-access-to-medicare-coverage/

[57] Berwick DM. Choices for the "new normal". JAMA. 2020; 323(21): 2125-2126. PMid: 32364589. https ://doi.org/10.1001/jama .2020 .6949

[58] Khorram-Manesh A, Carlström E, Hertelendy AJ, et al. Does the prosperity of a country play a role in COVID-19 outcomes? Disaster Med Public Health Prep. 2020. https ://doi.org/10.1017/dmp. 2020.304 